consented to their performance. The only permanent effect left behind is that, though his mental condition is perfectly clear, he is inclined to be what I would call "huffy." On the slightest provocation he is inclined to consider himself injured. He was discharged from hospital on December 14, 1896, and returned to his work a couple of weeks afterwards. About twelve months ago he was transferred from one station to another, and came to the conclusion that the transference was brought about by some enemies of his, although, as a matter of fact, he was getting lighter duty than what he had been doing. Sooner than submit to it he resigned, but was very sorry for it afterwards. At present he is in full possession of all his faculties.

\title{
PERFORATION OF THE MEMBRANA TYMPANI, THE RESULT OF BEING STRUCK BY LIGHTNING. ${ }^{1}$
}

\author{
By H. Macnaughton-Jones, M.D., F.R.C.S.
}

The details of the case are briefly as follows: On December 24 last an officer was sitting on the floor of his tent on blankets, drinking tea from an iron cup. A storm was passing at the time. He was not conscious of anything until he found himself, as he expressed it, paralyzed, with the exception of his left arm. $\mathrm{He}$ thinks that two hours may have elapsed between the time of his being struck until he was found. He was revived with brandy and strychnine injections, and vomited freely during his transit to the hospital three miles away. The hair on his left temple was burned, and also that on the pubes. There was an abrasion of the right breast, and a stripe about an inch and a half broad running down from this to the penis, from which it deflected over the right thigh, terminating in a mark "with a cut like a whip." There were still marks remaining on the skin when I last saw him at the end of March. There were also burns on both shoulders over the scapula, and another small one behind the right shoulder. The excoriation over the left shoulder was considerable. The hearing of the left ear was seriously affected, and the perforations were discovered a few days later. Curiously enough, the tent was not injured, and the flash had apparently struck within a few yards of it.

When I saw him the entire tympanic membrane was injected, 1902.

1 Communicated to the Otological Society of the United Kingdom, May 31 , 
und of a deep red colour. There were two perforations present, sne in the posterior superior quadrant, and the other below the umbo. The watch was heard just off contact, and a whisper close to the ear. The most troublesome symptom was a rather loud tinnitus. Some uneasiness and distress, hardly amounting to pain, were felt in the ear. There were no other evidences of nerve impairment elsewhere. There was little to be done in the way of treatment. I made periodical application of a weak solution of nitrate of silver to the membrane, keeping the ear protected with antiseptic gauze, and using occasionally Lucas's inflator. When I last saw him at the beginning of April the hearing was greatly improved, a whisper was heard at some 12 feet away, and, as estimated by Edelmann's Galton pipe, a tone of 10,000 vibrations per second, as compared with 35,000 in his unaffected ear.

The case is interesting, not only from the point of view of the marvellous escape he had, but also as it is the only one of which I am aware in otological literature in which perforation of the membrana tympani has been found as the result of lightning.

\title{
SOCIETIES' PROCEEDINGS.
}

\section{PROCEEDINGS OF THE BRITISH LARYNGOLOGICAL, RHINOLOGICAL, AND OTOLOGICAL ASSOCIATION.}

\author{
Ordinary Meeting held on Friday, May 9, 1902, at the Medical Society's \\ Rooms, 11, Chandos Street, Cavendish Square, IT.
}

\section{Mr. Lennox Browne, Treasuler, in the Chair.}

\section{Clinical Cases.}

Dr. Wyatt Wingrave read the following notes of a case of ()tomycosis (Aspergillus Niger), and exhibited a microscopical specimen of the fungus.

The patient, a young lady, aged nineteen, had complained of pain and irritation in the right ear for about two months, which recently became so severe as to demand advice.

There was some slight eczema of the meatus, and dirty flakes on the posterior meatal wall, extending on to the tympanic membrane, were visible. There were also several carious molars. The latter were extracted, and cocaine drops were ordered for the ears with slight relief. Next day syringing removed a cholesteatomatous mass like chewed newspaper, which microscopically proved to be epi- 